\title{
Satisfação sexual de mulheres entre 15 e 60 anos
}

Paulo César Ribeiro Martins* Cristiana Maria Torres Di Primio**

Carla Andrade Ramos***

\section{RESUMO}

O trabalho pretende investigar a satisfação sexual da mulher com o parceiro. Os sujeitos da pesquisa foram 122 mulheres, entre 15 e 60 anos, residentes na cidade de Passo Fundo-RS. O nível de escolaridade variou do $1^{\circ} \mathrm{Grau}$ incompleto ao $3^{\circ} \mathrm{Grau}$ completo. Em relação à atividade profissional, há mulheres: donas de casa, estudantes, professoras e profissionais liberais. Os sujeitos foram divididos nos seguintes grupos (Gr): 1. Mulheres com menos de 30 anos e mais de 30 anos. 2. Mulheres entre 22-29 anos e entre 45-51 anos. 3. Mulheres com $1^{9}$ grau e com $3^{2}$ grau. 4. Mulheres estudantes e mulheres professoras. 5. Mulheres professoras universitárias e mulheres donas de casa. Para a tabulação dos dados escolhemos o teste $t$, de student. Utilizamos um questionário contendo os dados de identificação e 11 perguntas objetivas. Os resultados obtidos foram: Gr1 - Mulheres com menos de 30 anos têm mais satisfação com o parceiro, na relação sexual, do

\footnotetext{
* Mestre em psicologia clínica.

** Psicóloga.

*** Psicóloga.

Recebido em 08.03.00
}

Aprovado em 28.03.00 
que mulheres com mais de 30 anos. Gr2 - Mulheres entre 22-29 têm mais satisfação do que mulheres entre $45-51$. Gr3 - Mulheres com $3^{\circ}$ grau têm mais satisfação do que mulheres com $1^{2}$ grau. $\mathrm{Gr} 4$ - Estudantes têm mais satisfação do que professoras e Gr5 - Mulheres professoras têm mais satisfação do que mulheres donas de casa.

Palavras chaves: Satisfação sexual, mulher, sexualidade.

“... para toda mulher há um tipo de sexualidade para cada tipo de insatisfação e também para cada tipo de satisfação".

Sartre (in Thiriet e Képès, 1996, p. 92)

A complexidade do mundo feminino permite que cada mulher vivencie sua sexualidade como uma experiência única e particular. É na amplitude desse universo, que se insere a questão do termo satisfação sexual. Pois, queiramos ou não, nossas atitudes têm relação direta com nossa satisfação sexual. Independente da idade, a harmonia da vida amorosa não se constitui numa questão simples. Foucault (1985b, 1985c) fala em sexualidade como experiência singular. Para o pensamento grego, o comportamento sexual é constituído como domínio de prática moral, uma força difícil de ser dominada e que exige um "domínio de si". Este "domínio" nos remete à noção de poder que só o sexo tem. O problema então é: Como dominar este desejo? Como conter esta força tamanha?

A resposta está na repressão sexual tão presente na história da humanidade, sendo a mulher tratada de maneira diferenciada. Assim, a mulher mantém internalizados em si mesma códigos de permissões e proibições relativos à sua sexualidade que irão, por sua vez, influenciar o nível de satisfação sexual. A satisfação, portanto, traduz-se pela correspondência do desejo feminino, com todas as implicações que o prazer da mulher traz e, principalmente, pelo interjogo entre a cultura repressiva, e o modo específico como cada mulher vivenciará suas experiências sexuais.

O desejo sexual é vivenciado sob a forma de sensações específicas que levam a mulher a buscar as experiências sexuais ou tornar-se receptiva a elas (Martins, 1994). A troca de carícias propicia, além do prazer mútuo, uma sensação de proteção, de segurança, tão importantes para a mulher; além do que, estabelece uma cumplicidade entre os parceiros, permitindo a formação da identidade do casal. Segundo Matarazzo (1992), a mulher é um ser tátil por excelência; deseja carícias, agrados, tem ternura à flor da pele. Para a mulher, num determinado momento, não há diferença entre emoção, sinceridade, doçura e erotismo.

A fantasia sexual, por ser inerente ao ser humano, é um exercício inevitável e saudável, refletindo necessidades e desejos que começam na infância e continuam a existir até à velhice (Costa, 1986).

A inibição do desejo feminino pode ocorrer se a mulher estiver em conflito consigo mesma, com o parceiro ou sentindo-se hostilizada. A inibi- 
ção pode ser seletiva no sentido de que pode ser mantido o funcionamento genital, já que algumas mulheres são capazes, mesmo de modo mecânico, ter lubrificação e orgasmo sem no entanto experimentar sensações de prazer (Kaplan, s/d).

Masters e Johnson (citado em Matarazzo, 1992) referem que muitas mulheres, durante a relação sexual, em vez de participarem, ficam "num canto" vendo o que vai acontecer. Estas mulheres colocam-se numa situação passiva, talvez como resultado de séculos de repressão.

Na cultura ocidental, a satisfação sexual da mulher tem sido representada pelo orgasmo tornando-se quase uma exigência que, às vezes, a impede de vivenciar de maneira plena, os prazeres da relação.

A fase do orgasmo, além de uma sensação psicológica, é um reflexo genital regido pelos centros neurais raquidianos. Os impulsos sensoriais, que desencadeiam o orgasmo, penetram a medula espinhal pelo nervo pudendo ao nível sacro, e o impulso eferente é de T11 para L2. A estimulação adequada provoca contrações rítmicas dos músculos ísquio e bulbo-cavernosos. Os estudos de Masters e Johnson (1985) e Kaplan (1983) demonstram que a estimulação clitoriana é ingrediente crucial na produção de orgasmos femininos. Estes estudos mostram que a dicotomia entre orgasmo clitoriano e vaginal é um mito. O orgasmo, via de regra, é disparado sobretudo pela estimulação clitoriana direta ou indireta, pelo mecanismo de tensão da glande clitoriana, sendo localizado na vagina e ao redor dela, podendo ser sentido pelo corpo todo (Martins, 1994; Haack e Martins, s/d). O funcionamento neurofisiológico do orgasmo, apesar de sua importância, só ocorre plenamente quando há um intercâmbio afetivo e adequado entre o casal, sendo que esta adequação sexual supõe entrega mútua e diálogo entre os parceiros.

\section{MÉTODO}

Para a tabulação dos dados escolhemos o teste " $\mathrm{t}$ ", de student, que é um método inferencial.

Um dos principais objetivos dos métodos inferenciais, também chamados "estatística inferencial" ou "métodos quantitativos", consiste em estimar os valores das características de uma população com base nas características obtidas por meio de amostras. Na impossibilidade de fazer uma pesquisa com toda uma população, toma-se uma amostra, ou seja, uma parte deste todo. A finalidade dos métodos inferenciais é precisamente comparar as diferenças ou não diferenças que existem entre os grupos de amostras e estender estes resultados a toda a população de cada um dos grupos.

Considere-se que, nas provas paramétricas, não é necessária uma amostragem demasiadamente grande. Visto que os parâmetros são conhecidos ou o fenômeno tende a se repetir nas mesmas condições, o teste $t$ é largamente usado. Acrescenta-se a isto o fato desse teste ser de grande po- 
der de eficiência, medindo e averiguando a significância das inferências de duas amostras (Marinho, 1980).

\section{SUJEITOS}

Os sujeitos da pesquisa são 122 mulheres, com idade ente 15 e 60 anos, residentes na cidade de Passo Fundo-RS. O nível de escolaridade variou do $1^{2}$ grau incompleto ao $3^{2}$ grau completo. Em relação a atividade profissional, há mulheres: donas de casa, estudantes, professoras e profissionais liberais. Todos os sujeitos foram determinados acidentalmente e divididos nos seguintes grupos:

$1^{2}$ - Mulheres com menos de 30 anos e mais de 30 anos;

$2^{2}$ - Mulheres entre 22-29 anos e entre 45-51 anos de idade;

$3^{2}$ - Mulheres com $1^{2}$ grau incompleto e completo e com $3^{2}$ grau incompleto e completo;

$4^{\circ}$ - Mulheres estudantes e mulheres professoras;

$5^{\circ}$ - Mulheres professoras universitárias e mulheres donas de casa.

\section{MATERIAL}

Optamos pela utilização de um questionário contendo, além da parte de identificação dos sujeitos, onze perguntas objetivas baseadas em Reich (1975), Kaplan (s/d, 1993, 1999), Heiman (1981), Dolto (1982), Botas (1986) e Costa (1986). O questionário foi baseado no que foi utilizado no estudo sobre a vivência de mulheres de alcoolistas (Martins, 1994).

\section{PROCEDIMENTO}

Para realizarmos a pesquisa, distribuímos o questionário, no primeiro momento, para mulheres de diferentes faixas de idade. As mesmas levaram o material para casa e, na medida em que respondiam, nos devolviam. No segundo momento, atribuímos uma pontuação para cada resposta, sendo que a $1^{\text {a }}$ opção valia 4 pontos e a $5^{\text {a }}$ opção, zero. Em seguida, utilizamos o teste $t$, de student, para verificarmos os resultados.

\section{RESULTADOS}

Para obtenção dos resultados, utilizamos o teste $t$, de student. A hipótese inicial foi de que ( $1^{\circ}$ grupo) mulheres com menos de 30 anos têm mais 
satisfação sexual, com o parceiro, na relação sexual, do que mulheres com mais de 30 anos. Os dados revelaram que com $\mathrm{a}=0,05$ as mulheres com menos de 30 anos de idade afirmam sentir mais satisfação sexual, no relacionamento com o parceiro, do que mulheres com mais de 30 anos de idade. A hipótese foi confirmada (gráfico 1).

A partir dos resultados da hipótese inicial, dividimos a amostra em 4 grupos, formulando novas hipóteses:

$2^{\underline{a}}$ grupo - Mulheres entre 22-29 anos têm mais satisfação com o parceiro, na relação sexual, do que as mulheres entre 45-51 anos. Os dados revelaram que com a $=0,05$, as mulheres entre 22-29 anos afirmam sentir mais satisfação sexual, no relacionamento com o parceiro, do que mulheres entre 45-51 anos de idade. A hipótese foi confirmada (gráfico 2).

$3^{\circ}$ grupo - Estudantes do sexo feminino do $3^{\circ}$ grau incompleto e completo têm mais satisfação com o parceiro, na relação sexual, do que estudantes do sexo feminino do $1^{\mathrm{g}}$ grau incompleto e completo. Os dados revelaram que com $\mathrm{a}=0,05$, as estudantes do sexo feminino do $3^{\circ}$ grau incompleto e completo afirmam sentir mais satisfação sexual, no relacionamento com o parceiro, do que estudantes do $1^{\circ}$ grau incompleto e completo. A hipótese foi confirmada (gráfico 3 ).

$4^{0}$ grupo - Estudantes do sexo feminino têm mais satisfação, na relação sexual com o parceiro, do que professoras. Os dados revelaram que com $\mathrm{a}=0,05$, as estudantes do sexo feminino afirmam sentir mais satisfação sexual, no relacionamento com o parceiro, do que professoras. A hipótese foi confirmada (gráfico 4).

$5^{\circ}$ grupo - Mulheres professoras com $3^{\circ}$ grau completo têm mais satisfação com o parceiro, na relação sexual, do que mulheres donas de casa. Os dados revelaram que com $\mathrm{a}=0,05$, as professoras com $3^{2}$ completo afirmam sentir mais satisfação sexual, no relacionamento com o parceiro, do que as donas de casa. A hipótese foi confirmada (gráfico 5).

\section{DISCUSSÃO DOS RESULTADOS}

O potencial para o prazer erótico é desenvolvido desde o nascimento e não acaba até a morte. A idade ajusta significativamente o componente biológico da sexualidade. A intensidade e a qualidade da resposta sexual variam consideravelmente nas diferentes idades. Os efeitos da idade não servem para nivelar as respostas sexuais, pois para cada pessoa, estas mudanças acontecem de acordo com suas histórias de vida. Na meia idade pode haver o auge da vida sexual feminina em função do declínio das inibições e inseguranças. Os estudos de Kinsey e Masters (in Bruno e Bruno, 1998) demonstram que as mulheres atingem o pico sexual nos últimos anos da casa dos 30 ou nos primeiros da casa dos quarenta, e daí declinam, num grau lento.

Nosso primeiro resultado foi de que mulheres com mais de 30 anos têm menos satisfação sexual do que as mulheres com menos de 30 anos. 
Leite e Bruns (1998), realizaram uma pesquisa com mulheres de 30 a 40 anos. Eles concluíram que há uma cisão entre o discurso e o comportamento dessas mulheres. Referem que a repressão sexual feminina se mantém com muita intensidade, revelando a dificuldade da mulher para lidar com sua sexualidade, impedindo uma vivência mais prazerosa com o parceiro.

As mulheres com menos de 30 anos sofrem uma ação menor da repressão. Borges e Rodrigues (1998) referem que, atualmente, através das revistas femininas, faz-se a construção de novas referências de sexualidade, sendo que as mulheres mais jovens assumem com mais facilidade a beleza da sexualidade como um impulso de vida, delegado a todos.

No segundo grupo estudado, nossos resultados revelam que as mulheres entre 22 e 29 anos têm mais satisfação com o parceiro do que as mulheres entre 45 e 51 anos. O que vem ao encontro dos resultados de Bruno e Bruno (1998). Isto sugere que as últimas mulheres sofrem as transformações resultantes da proximidade da menopausa, onde ocorre a baixa de hormônios estrogênicos e diminuição da lubrificação que pode causar atrofismo da mucosa vaginal e até dor na relação.

Vale lembrar que os valores sociais, morais e sexuais influenciam muito na determinação de uma vida sexual satisfatória. Lopes e Maia (1994) afirmam que a idade não dessexualiza o indivíduo, mas a sociedade sim, ou seja, a satisfação sexual depende da imagem que se faz do sexo e a influência que sofremos do meio. E depende, também, de como cada pessoa encara o passar dos anos e as mudanças advindas com os mesmos.

Os resultados demonstraram que mulheres com $3^{\circ}$ grau completo têm mais satisfação sexual do que as donas de casa, como também as estudantes de $3^{\circ}$ grau incompleto e completo têm mais satisfação do que as estudantes do $1^{\circ}$ grau incompleto e completo. Estes dados, talvez se devam ao fato de que as mulheres que estudaram, têm mais acesso às informações, adquirindo maior imunidade à tirania e à repressão que, segundo Cavalcanti (1998), têm vitimado muito mais as mulheres, enquanto a indulgência e a tolerância acobertam os homens.

O curioso é que nossos dados revelaram que mulheres professoras têm menos satisfação sexual do que estudantes, o que vem contrariar os dados de Silva, Pereira e Barcelos (1998), que referem que quem tem mais recursos financeiros e informações tem mais satisfação sexual. Em contrapartida, reafirmam os dados desta pesquisa que mulheres mais jovens (menos de 30 anos) têm mais satisfação do que mulheres mais velhas, já que as estudantes, via de regra, são mais jovens que as professoras.

\section{CONCLUSÃO}

O trabalho tem a finalidade de estudar a satisfação sexual da mulher com o parceiro. Nossos parâmetros para definir satisfação sexual obedece- 
ram os seguintes requisitos: desejo pelo parceiro; diálogo sobre vontade de "transar", satisfação/insatisfação sexual, preferências sexuais, fantasias sexuais, e prazer em tocar e ser tocada pelo parceiro.

Os resultados obtidos nos remeteram a uma reflexão sobre sexo, poder e repressão. Repressão esta que se intensifica no século XVIII com a ascensão da burguesia (Foucault, 1984; Martins e Soldatelli, 1998), onde a sexualidade é encerrada, escondida e reprimida.

Chauí (1988) relata que a repressão sexual existe desde que o mundo é mundo, mas o conceito de repressão sexual é novo, datado do século XIX, e se refere ao conjunto de interdições, normas e regras para controlar o exercício da sexualidade.

Como exemplo da repressão sexual do início do século, Chauí (1988) cita o livro "Iniciação Sexual - Educacional (Leitura Reservada)" de Oswaldo Brandão da Silva, publicado em 1938, onde o autor escreve que: “... as meninas não devem lê-lo porque devem ser mantidas na inocência para que sejam iniciadas ao sexo apenas por seus maridos que, antes do casamento, devem ser castos e respeitar a virgindade da futura esposa. As meninas estão excluídas porque não necessitam de informação, visto que não terão vida sexual antes do casamento" (p. 18).

Atualmente, no final do século XX, segundo Berenstein (1998), as filhas é que ensinam a sexualidade às mães. Em função disto, não é de se admirar que as mulheres mais jovens e as mais instruídas tenham maior satisfação sexual do que as mais velhas (mais de 30 anos) e menos instruídas.

\section{REFERÊNCIAS BIBLIOGRÁFICAS}

1. BERENSTEIN, E. Evolução da feminilidade. I Jornada de Sexualidade Humana. Chapecó, 1998.

2. BORGES, D. T. B. e RODRIGUES, J. F. S. Imagens femininas e a liberação do desejo: mídia e sexualidade. Anais do $4^{\circ}$ Congresso Paulista de Sexualidade Humana. São Paulo, 1998.

3. BOTAS, P. C. L. e col. A perversão da ternura. In: COSTA, M. (org.). Macho, masculino, homem. 6. ed. São Paulo. LP\&M, 1986.

4. BRUNO, Z. V. e BRUNO, Z. V. Os efeitos da idade sobre a sexualidade. Revista Brasileira de Sexualidade Humana. 9(1),18-22, 1998.

5. CAVALCANTI, M. Sexualidade feminina: ontem, hoje e amanhã. Revista Brasileira de Sexualidade Humana. 9(1), 35-44, 1998.

6. CHAUÍ, M. Repressão sexual-essa nossa (des)conhecida. 12. ed. São Paulo: Brasiliense, 1991.

7. COSTA, M. Sexualidade na adolescência, dilemas e crescimento. 5. ed. São Paulo: LP\&M, 1986.

8. DOLTO, F. Sexualidade feminina. São Paulo: Martins Fontes, 1984.

9. FOUCAULT, M. História da sexualidade I. A vontade de saber. 7. ed. Rio de Janeiro: Graal, 1985a. 
10. FOUCAULT, M. História da sexualidade II. O uso dos prazeres. 4. ed. Rio de Janeiro: Graal, 1985b.

11. FOUCAULT, M. História da sexualidade III. O cuidado de si. Rio de Janeiro: Graal, 1985c.

12. HAACK,.C. G. e MARTINS, P. C. R. Sexualidade humana. Enciclopédia Educar III. O homem em busca de educação. Erechim: Educar, s/d.

13. HEIMAN, J., LOPICCOLO, L., LOPICCOLO, J. Descobrindo o prazer. 3. ed. São Paulo: Summus, 1981.

14. KAPLAN, H. S. A nova terapia do sexo. Rio de Janeiro: Nova Fronteira, s/d.

15. KAPLAN, H. S. O desejo sexual e novos conceitos e técnicas da terapia do sexo. Rio de Janeiro: Nova Fronteira, 1983.

16. KAPLAN, H. S. Transtornos do desejo sexual. Regulação disfuncional da motivação sexual. Porto Alegre: Artes Médicas, 1999.

17. LEITE, C. R. V. S. e BRUNS, M. A. T. Quando o oculto se desvela: a sexualidade da mulher de 30 a 40 anos. Anais do $4^{2}$ Congresso Paulista de Sexualidade Humana. São Paulo, 1998.

18. MARINHO, P. A pesquisa em ciências humanas. Rio de Janeiro: Vozes, 1980.

19. MARTINS, P. C. R. Considerações sobre como mulheres de alcoolistas vivenciam sua sexualidade. Revista Médica do HSVP. 6(15) 19-21, 1994.

20. MARTINS, P. C. R. e SOLDATELLI, M. M. Sexo e poder: uma reflexão histórica. Revista Brasileira de Sexualidade Humana. 9 (1), 29-34, 1998.

21. MARTERS, W. H. e JOHNSON, V. A inadequação sexual humana. São Paulo: Roca, 1985.

22. MATARAZZO, M. H. Amar é preciso. Os caminhos para uma vida a dois. 3. ed. São Paulo: Gente, 1992.

23. REICH, W. A função do orgasmo. São Paulo: Circulo do Livro, 1975.

24. SILVA, R. A., PEREIRA, E. S. e BARCELOS, N. N. S. Família e sexualidade no século XX. Anais do $4^{a}$ Congresso Paulista de Sexualidade Humana. São Paulo, 1998.

25. THIRIET, M. e KÉPÈS, S. Mulheres de 50 anos. Como viver plenamente esta nova idade. 4. ed. São Paulo: LP\&M, 1996. 
GRÁFICO 1 Mulheres com menos de 30 anos têm mais satisfação sexual, com o parceiro, do que mulheres com mais de 30 anos

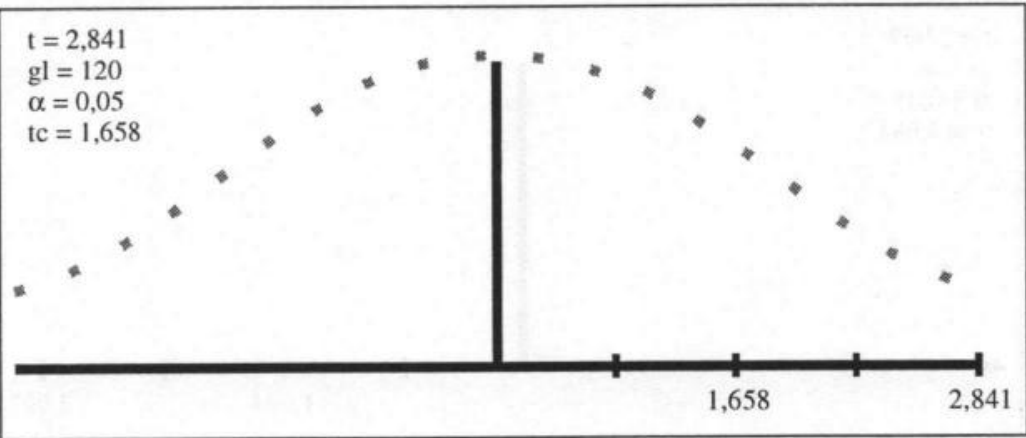

GRÁFICO 2 Mulheres entre 22-29 anos têm mais satisfação sexual, com o parceiro, do que mulheres entre 45-51 anos

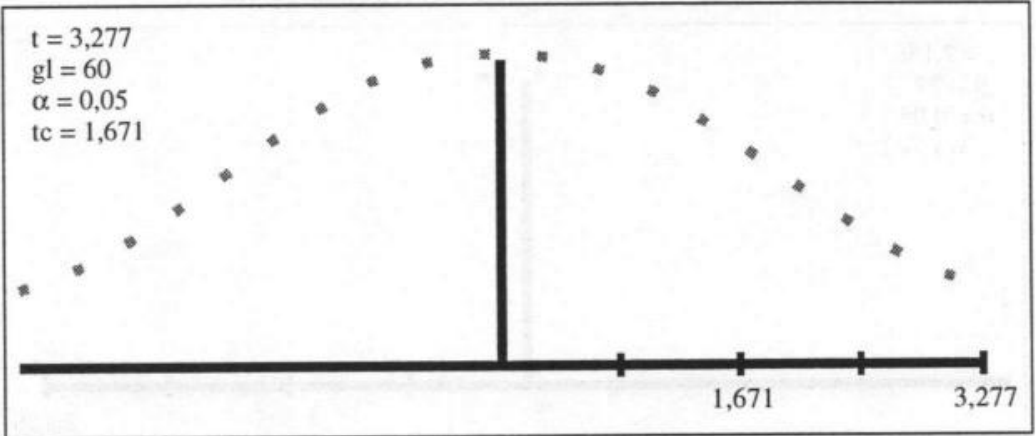

GRÁFICO 3 Estudantes do $3^{2}$ grau incompleto e completo têm mais satisfação sexual, com o parceiro, do que estudantes do $1^{\circ}$ grau incompleto e completo

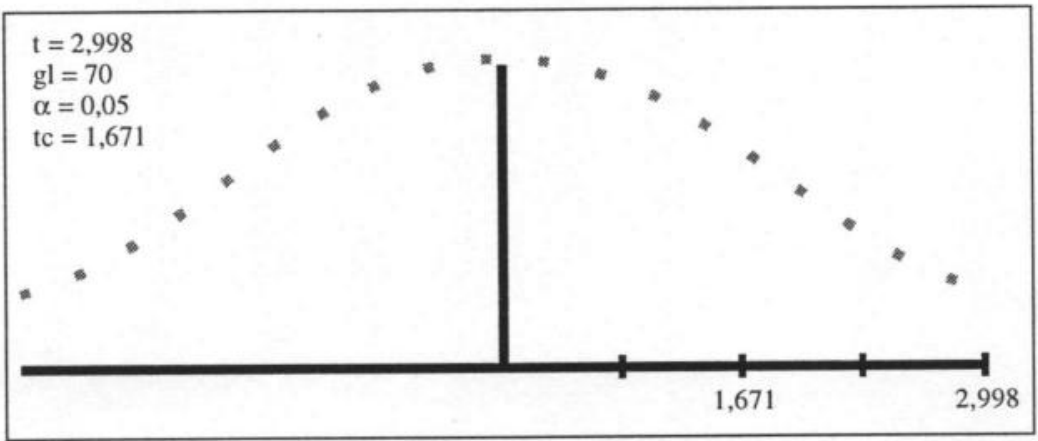


GRÁFICO 4 Estudantes têm mais satisfação na relação sexual com o parceiro do que professoras

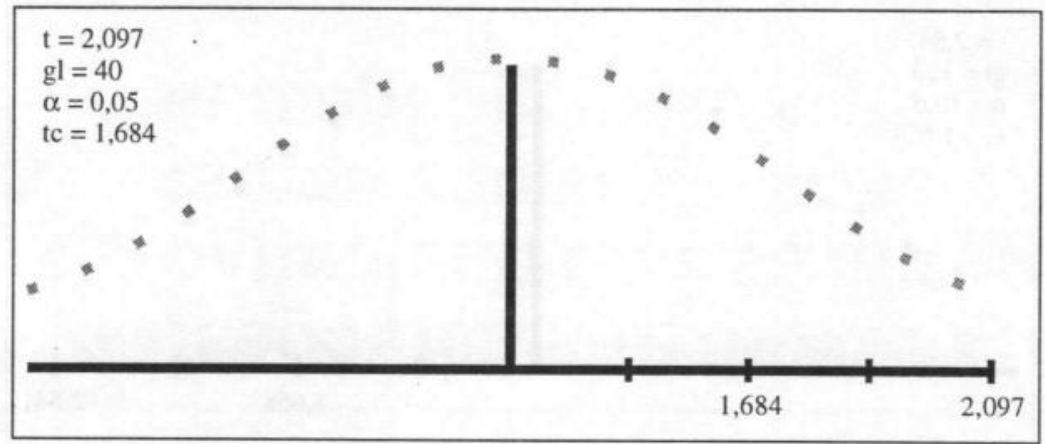

GRÁFICO 5 Professoras com $3^{\circ}$ grau completo têm mais satisfação sexual, com o parceiro, do que donas de casa

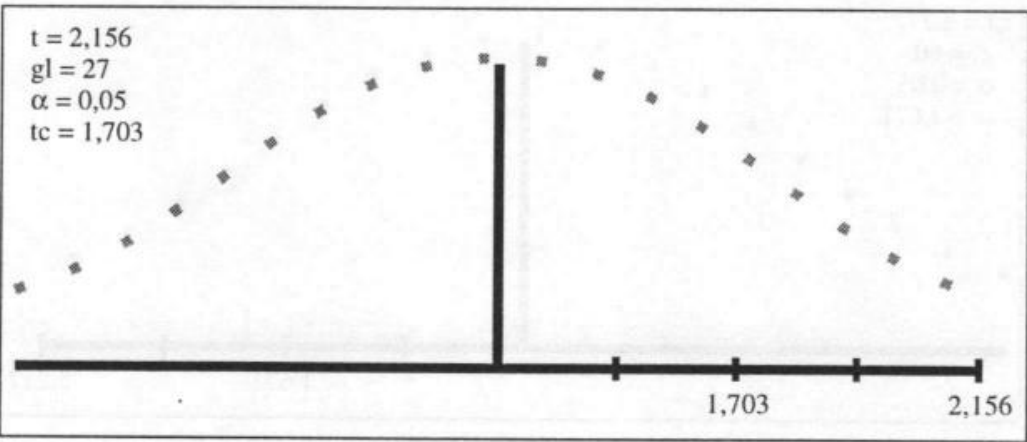

